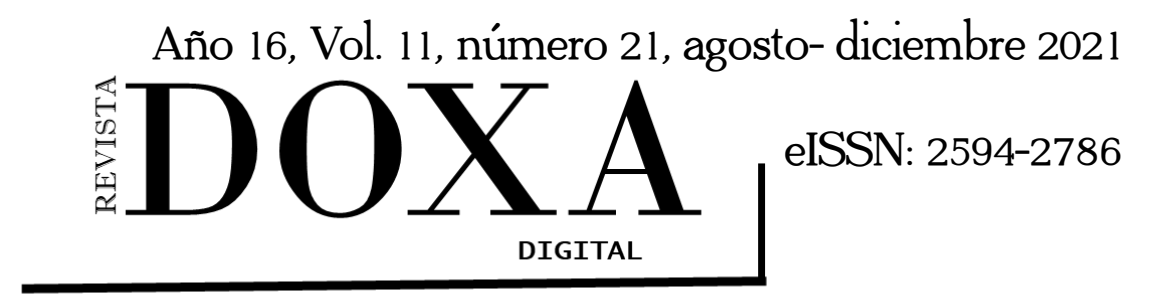

Sección: Ciencias Sociales

Recibido: Marzo 2021

Aceptado: Junio 2021

DOI: $10.52191 /$ rdojs.2021.219

Pág.: $72-93$

\title{
Gestión del agua potable en Piedras Negras, Coahuila
}

\section{Management of drinking water in Piedras Negras, Coahuila}

\author{
Jesús Frausto Ortega *
}

\section{RESUMEN}

El objetivo del artículo es hacer una revisión sobre la gestión del agua potable en Piedras Negras, Coahuila, enfatizando en la eficiencia en su manejo en el marco de la Nueva Gestión del Agua. Se revisaron indicadores de 2003 a 2019 de diversas fuentes estadísticas; del Organismo Operador se entrevistó al Gerente General y a la responsable del Programa de Cultura del Agua y se consultaron minutas del Consejo de Administración. Hay una cobertura del 98 por ciento, pero el reto es en su eficiencia: el 40 por ciento del agua se desperdicia y se cobra el 88 por ciento.

PALABRAS CLAVE: Palabras clave: Nueva Gestión del Agua, agua potable, agua en la frontera, Piedras Negras, Frontera Norte.

\begin{abstract}
The objective of the article is to review the management of drinking water in Piedras Negras, Coahuila, emphasizing the efficiency of its management within the framework of the New Water Management. Indicators from 2003 to 2019 from various statistical sources were reviewed; of the Operating Agency, the General Manager and the person in charge of the Water Culture Program were interviewed and minutes of the Board of Directors were consulted. There is a 98 percent coverage, but the challenge is in its efficiency: 40 percent of the water is wasted and 88 percent is charged.
\end{abstract}

KEY WORDS: New Water Management, drinking water, water at the border, Piedras Negras, Northern Border.

\footnotetext{
* Doctor en Ciencias Sociales con especialidad en Estudios Regionales por El Colegio de la Frontera Norte (EL COLEF). Investigador Asociado B en EL COLEF en la Sede de Piedras Negras. Contacto: jesusfrausto@colef.mx
} 
Año 16, Vol. 11, número 21, agosto-diciembre

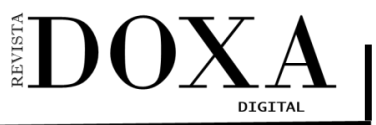

pISSN: 2395-8758 eISSN: 2594-2786
Sección: Ciencias Sociales

DOI: 10.52191/rdojs.2021.219
Jesus Frausto Ortega

Gestión del agua potable...

Pág.: 72-93

\section{Introducción}

El crecimiento de la población, de la urbanización, de las actividades económicas e industriales de las ciudades ha generado una mayor demanda de los recursos naturales y entre ellos el agua. La historia de los usos del agua en México en el siglo XX "(...) contiene el esfuerzo de la sociedad por acrecentar el control y aumentar el consumo del líquido (...)" (Aboites, Birrichaga y Garay, 2010: 42). Pero garantizar el servicio para toda la sociedad en México siempre ha sido un ideal más que una realidad ya que por lo general en la mayoría de las ciudades no se cubre al cien por ciento de sus habitantes y sobre todo su falta la padecen los pobres que viven en las periferias de las localidades o en las áreas rurales.

La construcción de grandes infraestructuras (presas, acueductos, canales, entre otros) se fue desarrollando para atender las demandas primero en la agricultura, y después en las poblaciones urbanas-rurales y para el desarrollo industrial, o para la generación de electricidad. Así, después de 1960 hay un incremento de la inversión en presas hidroeléctricas y para la provisión de agua a las ciudades (Aboites, Birrichaga y Garay, 2010: 41). Por muchos años en México se enfatizó en la oferta de la infraestructura hídrica para dar cobertura a los usuarios que demandaban el recurso. En el caso del agua potable se fue atendiendo principalmente a las grandes ciudades. En la urgencia por atender una mayor demanda de la población se olvidaron aspectos de la calidad o eficiencia en la gestión del agua. Lo que se tradujo por lo regular en derroches y abusos en el uso del líquido y en su contaminación. En síntesis, ante la necesidad de introducir infraestructura -potabilizadoras, redes de agua potable, plantas de tratamiento, por ejemplo-, en condiciones, por lo general, de escasez de recursos económicos y de un manejo político del agua y de los servicios, entre otros factores, el cuidado ambiental y buen uso del agua se fueron desatendiendo.

Frente a las tradicionales estrategias de la oferta del recurso se impone la necesidad de una gestión de la demanda, con el objetivo de incentivar la eficiencia, la conservación y el ahorro. En los ochenta se transfieren los servicios de agua y drenaje a los municipios, entre otras cosas para mejorar las demandas locales. En los noventa se crean los organismos operadores de agua (OOA) para hacer la gestión del agua eficiente y sustentable. No obstante, hoy en día en el país la gestión de la demanda enfrenta muchos retos. Así, en México parece haber un consenso que presenta a los OOA como un sector ineficiente e incapacitado para realizar las funciones institucionales asignadas (Armendáris, 2010). Otro aspecto que quedó al margen fue la participación de la población en la gestión del agua potable, ya que su involucramiento es mínimo y limitado. La política hídrica privilegia una participación dirigida desde las instancias de gobierno limitando a la sociedad y usuarios en 
Año 16, Vol. 11, número 21, agosto-diciembre

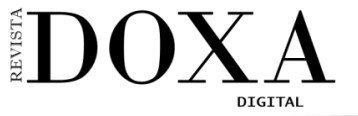

Sección: Ciencias Sociales

DOI: 10.52191/rdojs.2021.219
Jesus Frausto Ortega

Gestión del agua potable...

Pág.: 72-93

la toma de decisiones sobre la implementación de la gestión del agua. No obstante que en la Nueva Gestión del Agua (NGA) la participación es importante para un mejorar manejo y conservación del líquido.

Las condiciones descritas no son ajenas en las poblaciones fronterizas como la de Piedras $\mathrm{Ne}-$ gras ya que también enfrentas esas problemáticas. En la gestión del agua potable se observa una especie de paradoja: por una parte, hay coberturas altas de agua potable en estas ciudades; pero por otra, la prestación del servicio enfrenta retos importantes en su buena gestión, traduciéndose entre otras cosas- en un manejo deficiente del agua que implica tanto a los organismos que la proveen como a la población usuaria del recurso. La ineficiencia en el manejo del agua tiene que ver con aspectos operativos, administrativos y financieros de dichos organismos. En un contexto de su escasez. Algunos de los problemas que enfrentan los OOA son: pérdidas de agua, carteras vencidas en el cobro, tarifas por debajo del costo de la producción de agua, infraestructura vieja, falta de recursos financieros para operar, tomas clandestinas, etcétera (Pineda Pablos, 2008). Para Arreguin y otros (2010) en las ciudades las pérdidas de agua van de 30 a 50 por ciento y las posibilidades de recuperar volúmenes de líquido están asociadas -entre otras- a acciones como aumentar la eficiencia de los OOA y fortalecer su autosuficiencia financiera y el tratamiento de sus aguas y su reúso (p. 60).

En Piedras Negras se reconoce la ineficiencia en la administración del agua entre otras cosas por la falta de sistemas de medición del agua o falta de tarifas adecuadas, lo que conduce a ineficiencias financieras para administrar los organismos o ineficiencias técnicas de los sistemas (Gobierno de Coahuila, 2012). Además, la participación social en la política del agua local es escasa y restringida a ciertos sectores que se representan en las cámaras locales y donde el ciudadano común no aparece (Arzaluz, 2011). Si bien esto último es parte de las conclusiones de la autora para tres municipios fronterizos: Acuña, Coahuila y Reynosa y Nuevo Laredo, Tamaulipas, es el común de los organismos de la frontera. Y la política del cuidado del agua por parte de la ciudadanía impulsada por los OOA se restringe a aquella población que atienden los organismos a través de los Programas de Cultura del Agua (PCA).

El objetivo del trabajo es hacer una revisión inicial sobre la gestión del agua potable en Piedras Negras, Coahuila, centrando la reflexión sobre el problema de la eficiencia en su manejo. Esto con el propósito de documentar sobre la idea de que no obstante que se ha alcanzado una cobertura alta de agua en la ciudad, aún hay retos en la buena gestión del recurso. Como parte del análisis, se hace una breve referencia sobre la participación de la población en la gestión. Además de esta 
Año 16, Vol. 11, número 21, agosto-diciembre

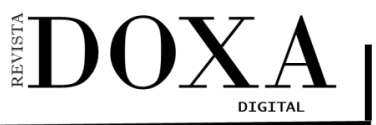

pISSN: 2395-8758 eISSN: 2594-2786
Sección: Ciencias Sociales

DOI: 10.52191/rdojs.2021.219
Jesus Frausto Ortega

Gestión del agua potable...

Pág.: 72-93

introducción, la segunda sección aborda sobre la Nueva Gestión Hídrica; en la tercera se trata la metodología; en la cuarta sobre la gestión del agua en Piedras Negras; en la quita se hacen las conclusiones y algunas recomendaciones, finalmente se expone la bibliografía.

\section{La Nueva Gestión Hídrica}

En el contexto de un desarrollo insustentable y en un esquema de apropiación casi sin límites de los recursos naturales y como tal los hídricos por parte del ser humano, se vio al agua como un recurso abundante e ilimitado para el beneficio de éste. Así, se desarrollaron infraestructuras para almacenar el agua (grandes presas) y conducirla (acueductos y canales para el riego de la agricultura y redes de agua para abastecer a las ciudades) de cuencas hídricas cada vez más lejanas conforme se incrementaban las demandas. Esa tecnología permitía ofertar la abundancia del agua sin importar la distancia y las condiciones geográficas. Ese modelo de apropiación trajo impactos negativos. Por ello en los 80 se comienza a hablar de una crisis ambiental y de una crisis del agua. Inicia la preocupación por su escasez (agotamiento) y su degradación (contaminación).

La preocupación por una buena gestión del agua inicia a partir del informe de la Comisión Bruntald y la propuesta del concepto de desarrollo sustentable que prevé que éste debe satisfacer las necesidades de la población presente sin comprometer las de la futura (Ver Naciones Unidas, 1987). En materia del agua, se contempla su preservación y buen uso/manejo considerando el beneficio de la sociedad actual como la venidera. Con la Conferencia de Dublín de 1992 se fomenta la participación de la sociedad en la gestión y uso del agua y que ésta debe tener un valor económico; además de que es un recurso finito y vulnerable y se requiere una gestión integral con un enfoque de cuencas hidrológicas en un contexto de sustentabilidad (Ver SER/SMARNAT, 2008). Y en la de Río de Janeiro, también en 1992, que refrenda lo anterior, mediante la instauración de la Agenda 21 -que después deriva en la implementación de Agendas Locales- que entre otras cosas promueve una gestión integral de los recursos hídricos (GIRH) en el marco de un desarrollo sustentable (Ver ONU 1997 y ONU, s/f). Son principios que se incorporan en la política y Nueva Gestión del Agua (NGA).

La crisis del agua ha dado pauta a la valoración del recurso en ocasiones bajo visiones contradictoras que también lleva a concebir soluciones diferenciadas: el agua como una mercancía que conlleva a su privatización; y la otra, vista como un bien común que entre otras cosas pugna por una gestión comunitaria o de autogestión (Ver Torregrosa et al, 2010). Imperando sobre todo, en la gestión del agua, la primera valoración y en México no es la excepción. Además, en la participación 
Año 16, Vol. 11, número 21, agosto-diciembre

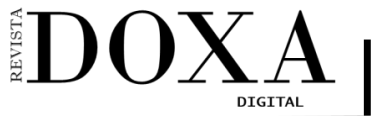

pISSN: 2395-8758 eISSN: 2594-2786
Sección: Ciencias Sociales

DOI: 10.52191/rdojs.2021.219
Jesus Frausto Ortega

Gestión del agua potable...

Pág.: 72-93

de dicha visión se van incorporando nuevos actores e instituciones internacionales impulsoras de dicha gestión. Instancias que dese esos años han estado impulsando de manera enérgica la privatización y la distribución del agua basada en el mercado (Shiva, 2007). El Fondo Monetario Internacional, el Banco Mundial y el Banco Interamericano de Desarrollo, principalmente, presionan a los países pobres para adoptar los nuevos modelos de gestión en las legislaciones y en las políticas públicas para facilitar los cambios y de la empresa en la gestión del recurso, que en el contexto urbano se traduce en la prestación de los servicios de agua y saneamiento por la iniciativa privada. Así, en un contexto de crisis del agua - escasez de agua y manejo insustentable del recurso, entre otros-, las propuestas de la Cumbre de Río y de Dublín, y otras, fueron adoptadas e impulsadas por esos organismos que presionaron en los años 90 para adoptar las nuevas políticas del agua en los países pobres como México (Dávila Poblete, 2006). Como señalan Rolland y Vega (2010: 178) "En la actualidad el agua es considerada en México más como un bien económico que como un bien común en el sentido estricto del término".

Armendáris (2010) menciona que con la crisis ambiental -y con ello la del agua-en forma paralela surge una crisis del Estado, y como parte de ello del papel de éste y de la sociedad con relación a los recursos; esas crisis trajeron consigo propuestas de cambio promovidas desde el ámbito internacional. La misma autora refiere que se fueron desarrollando conceptos para esa NGA. Además de el de sustentabilidad de los recursos hídricos, los de GIRH y el de Gobernanza del Agua (GA): de esa manera, la gestión integrada del agua es el principio básico de la nueva gestión del recurso basada en la gobernanza (p. 12). La GIRH se define como "un proceso que promueve el desarrollo y manejo coordinados del agua, la tierra y otros recursos relacionados, con el fin de maximizar el bienestar económico y social resultante de manera equitativa, sin comprometer la sostenibilidad de los ecosistemas vitales" (GWP, 2011: 1). La GA está relacionada con el buen uso del agua y con la participación de la sociedad en las decisiones sobre el recurso y reconoce a la cuenca como el territorio para la gestión (ANEAS, 2015: 1). En términos generales -se puede decir- que lo que se busca con dichos conceptos en una gestión más sustentable del agua con la corresponsabilidad de la sociedad, del gobierno y de los actores de interés, en donde se considere los diversos usos del recurso hídrico y los ecosistemas asociados, en un contexto de cuencas hidrológicas.

En el contexto de esa crisis -la ambiental y la del Estado-, se plantean nuevas formas de intervención de éste -y de la sociedad- en la gestión y usos de los recursos hídricos, sobre todo en los países en vías de desarrollo. Como parte de esa crisis, la falta de recursos económicos de estos países y su endeudamiento externo afectó en sus capacidades para atender las necesidades de 
Año 16, Vol. 11, número 21, agosto-diciembre

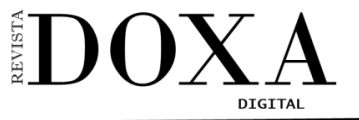

pISSN: 2395-8758 eISSN: 2594-2786
Sección: Ciencias Sociales

DOI: 10.52191/rdojs.2021.219
Jesus Frausto Ortega

Gestión del agua potable...

Pág.: 72-93

sus poblaciones, entre ellos en el desarrollo de infraestructura y de servicios, de agua. En ese sentido, Dávila Poblete (2006) hace referencia -entre otras cosas- que es sobre todo a inicios de los años 90 cuando la política de globalización incide en las políticas económicas y limita la actuación económica de los Estados-nación. Lo que influyó en la privatización de empresas estatales y en el impulso en la participación social con énfasis en la empresa privada para que se corresponsabilizara en la preservación y conservación del agua (p. 55-56).

México fue uno de los primeros en modificar sus política públicas: trasferir funciones y atribuciones que tenía el Estado, entre ellos los servicios de agua y alcantarillado (Dávila Poblete, 2006). Rolland y Vega (2010) sitúan la gestión del agua en México en dos momentos históricos con una frontera situada en 1992. El primero, marcado por un modelo de gobierno centralista en donde la administración del agua era responsabilidad de instituciones federales; el segundo, por un gobierno marcado por la descentralización y la democratización en la gestión del agua así como en su privatización. De acuerdo a Schmidt (2005) la Ley de Aguas Nacionales (LAN) tuvo el propósito de fortalecer la concesión de los derechos de uso del agua y favorecer la inversión privada, para lo cual entre los instrumentos establecidos fueron una mayor participación de los usuarios. Pineda Pablos (2002), por su parte, habla de tres momentos en la gestión del agua: la etapa centralista (de 1948 a 1983), la de la municipalización (a partir de 1983 hasta 1989) y la de la promoción de los organismos operadores autónomos manejados como empresas a partir de 1989. La coincidencia es -se puede decir- que después de 1990 se inicia una gestión del agua con énfasis en su privatización.

En México a partir de los años ochenta con la reforma al artículo 115 de la Constitución en 1983 se transfiere a los municipios la responsabilidad de los servicios de agua potable y el alcantarillado y en los 90 el de saneamiento. En estos años se refuerza esa política con la creación de la Comisión Nacional del Agua (entonces CNA, hoy Conagua) en 1989 y con la implementación de la LAN de 1992 y con la reforma de ésta en 2004. En el nivel estatal se crean las leyes de agua y sus dependencias correspondientes y en el caso que nos ocupa la Comisión Estatal de Aguas y Saneamiento de Coahuila y la Ley de Aguas de los Municipios del Estado de Coahuila.

Se considera a los años 90 como el punto de partida de la Nueva Política Hídrica en el país. Dos instituciones artífices de la concepción y organización de dicha política y de la gestión del agua urbana son la Conagua y la LAN, ya señaladas. En ellas se contemplan los principios de la NGA propuestas a nivel internacional. La GIRH y por cuencas es uno de los principios de la política hídrica del país, así como el valor económico, social y ambiental del agua; en donde la tarea de preservación en cantidad, calidad y sustentabilidad es labor del estado y de la sociedad (Ver Cámara de 
Año 16, Vol. 11, número 21, agosto-diciembre

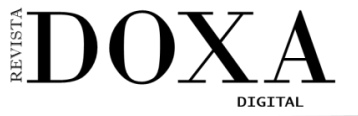

pISSN: 2395-8758 eISSN: 2594-2786
Sección: Ciencias Sociales

DOI: $10.52191 /$ rdojs.2021.219
Jesus Frausto Ortega

Gestión del agua potable...

Pág.: 72-93

Diputados, 1992). Ese énfasis del valor económico en la política del agua en el país se contempla en dicha ley: el agua debe generar los recursos económicos necesarios para realizar las tareas asociadas bajo el principio de que el agua paga el agua; los usuarios beben pagar el agua por su explotación, uso o aprovechamiento bajo el principio de usuario pagador; y en el caso de la calidad los usuarios que la contaminan deben restaurar su calidad bajo el principio de quien contamina paga (Ver. Art. 14 BIS 5, XV, XVI y XVII). Además, como parte de esa NGA, la política hídrica considera nuevos actores en dicha gestión. Además de los señalados (Conagua, Comisiones Estatales del Agua), los Consejos de Cuenca; los Organismos de Cuenca, los Usuarios y la Sociedad, así como los OOA que son vistos como empresas que pueden obtener concesiones para prestar los servicios de agua potable o en colaboración con dependencias públicas. Éstos además pueden concesionar los servicios a particulares (Ver Cámara de Diputados, 1992; Congreso del Estado, 2009). En ese marco de la descentralización como parte de la NGA, los derechos y explotación que antes se consideraba a los municipios y a las entidades locales, ahora se les concesiona a los organismos operadores, para mejorar la cantidad y calidad del agua (ver Carrillo y Constantino, 2010). Otros actores de la NGA son las empresas que prestan los servicios de agua y que por lo regular son multinacionales como Vivendi, Suez y otras que por lo general se asocian para ello con empresas locales.

Entre otras cosas, este nuevo arreglo institucional contempla una mayor eficiencia económicafinanciera y ambiental-sustentable en la gestión del agua. Y para ello los nuevos OOA son las instancias (empresas) que se vislumbraron para hacer esa tarea ante el cúmulo de problemas que enfrentaban en dicha labor los organismos públicos. Entre éstos la falta de recursos económicos para enfrentar las necesidades de infraestructura para abastecer a la sociedad en crecimiento, así como diversos problemas asociados a la eficiencia en la prestación de los servicios. En este esquema, las tarifas de agua -su valor económico- (hay que cobrar su valor real) son un elemento central en la NGA para la autosuficiencia financiera de los OOA. Por ello, el marco normativo promueve el cobro del agua y su corte del servicio por falta de pago. Y si bien la política hídrica y la gestión del agua contemplan el valor ambiental y ecológico del agua, en el contexto local en la prestación del agua potable predomina principalmente el valor económico del agua vía las tarifas del servicio -como se mencionó-. Por ello se institucionalizó el que los OOA las implementaran aunque en la práctica son los congresos estatales quienes las autorizan. En el ámbito del agua potable, la valoración ambiental se reduce al tratamiento de las aguas residuales y su reúso que son competencia de dichos organismos o a los concesionarios, donde aún hay retos pendientes por tratar toda el agua y reusarla y no contaminar los cuerpos de agua. Otra limitante en el cuidado del agua y sus fuentes es que los 
Año 16, Vol. 11, número 21, agosto-diciembre

DOXA
Sección: Ciencias Sociales

DOI: 10.52191/rdojs.2021.219
Jesus Frausto Ortega

Gestión del agua potable ...

Pág.: 72-93

OOA no tienen competencia sobre éstas sino que es la Conagua y lo que importa es tener agua antes que conservarla.

La Conagua, como parte de la Nueva Política de la Gestión Hídrica, ha concebido formas de incidir en la eficiencia de la gestión del agua de los OOA con la creación de programas a implementar por los organismos y que apoyan con recursos económicos y capacitación a dichas empresas. Proyectos como Promagua, Prodder, Apazu, principalmente: "buscan auxiliar a los estados y municipios para el mejoramiento cuantitativo y cualitativo de los servicios de agua potable, alcantarillado y saneamiento en zonas urbanas" (Valencia y Molina, 2013):

Cuadro 1. Programas para eficientar los servicios de agua, drenaje y medio ambiente

\begin{tabular}{|c|c|c|}
\hline Programa & Año & Características principales \\
\hline Apazu & 1990 & $\begin{array}{l}\text { Incrementar las coberturas de agua potable y alcantarillado. Aplica a pobla- } \\
\text { ciones de } 2500 \text { o más habitantes. }\end{array}$ \\
\hline Prodder & 2002 & $\begin{array}{l}\text { Devolver a los OOA los pagos por derechos de agua para mantenimiento y } \\
\text { modernización y mejorar la eficiencia de la infraestructura; mejorar los servi- } \\
\text { cios prestados. Aplica para población de } 2500 \text { o más. }\end{array}$ \\
\hline Promagua & 2001 & $\begin{array}{l}\text { Modernizar los servicios de OOA a través de recursos públicos y privados. } \\
\text { Permite usar recursos privados como complemento a los recibidos del Progra- } \\
\text { ma. Para OOA de poblaciones mayores a } 50 \text { mil habitantes. Fomentar la efi- } \\
\text { ciencia física, comercial y la autosuficiencia, así como promover el cuidado } \\
\text { ambiental }\end{array}$ \\
\hline
\end{tabular}

Fuente: elaboración con información de Valencia y Molina, (2013) y de Armendáriz, 2010.

Una forma de ver el desempeño de los OOA es a través de los conceptos implementados por la Conagua: eficiencias: física, comercial, global y agua no contabilizada, entre otros. Armendáris (2010) menciona a esos indicadores como los que conforman la eficiencia en el manejo del agua. Conagua (2014a) los define de la siguiente manera:

La eficiencia física se estima en porcentaje, como el cociente entre el volumen de agua facturado entre el volumen de agua producido. La eficiencia comercial se estima en porcentaje, como el cociente entre el volumen de agua recaudado entre el volumen de agua facturado. La eficiencia global se define como el producto de las dos eficiencias anteriores. La eficiencia de cobranza se estima en porcentaje, como el cociente entre el importe de agua recaudado entre el importe de agua facturado.

Ante condiciones de escasez de agua y de distribución desigual en México, es importante hacer un uso eficiente y sustentable del recurso. Porque se habla que la escasez del recurso hídrico tiene que ver en muchos casos más bien con su mala gestión que con su escasez natural (Carrillo y Constantino, 2010: 119), Y como mencionan Valencia y Molina (2013: 47): "Es más barato y más 
Año 16, Vol. 11, número 21, agosto-diciembre

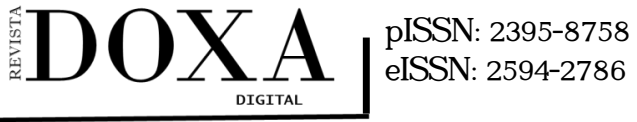

Sección: Ciencias Sociales

DOI: $10.52191 /$ rdojs.2021.219
Jesus Frausto Ortega

Gestión del agua potable...

Pág.: 72-93

sensato en invertir en suprimir fugas y usar agua de forma más eficiente que buscar nuevas fuentes de abastecimiento". Pineda Pablos y otros (2010) enfatizan:

(...) la manera más económica y efectiva de enfrentar el crecimiento demográfico y una eventual menor disponibilidad de agua es con una gestión más eficiente que reduzca las pérdidas de agua y haga innecesarias nuevas fuentes de suministro, así como con una efectiva política comercial que reduzca al mínimo la tasa de usuarios que no pagan y haga del cobro volumétrico un incentivo para el ahorro y conservación del recurso (...).

\section{La participación de la población}

La participación de la sociedad es una parte importante dentro de la NGA en México para hacer una mejor gestión y uso del agua. Es esencial para la implementar la GIRH que promueve la política hídrica y para la sustentabilidad de los recursos naturales. Así, es fundamental para el manejo eficiente del agua y para la conservación del recurso. El nuevo modelo de la gestión del recurso hídrico en México transita a la gobernanza del agua a partir de los años 90 y en ésta la participación es esencial para lo anterior (Ver Musseta 2009). Para Carabias y Landa (2005: 139) la GIRH no puede ser responsabilidad solo del gobierno ya que para la solución de los problemas del agua se requiere la participación de los usuarios, las comunidades y de la sociedad. Pero además porque es un derecho que ésta se involucre mediante reglas en las decisiones públicas. Pero no todos tienen el poder de participar en la política del agua. Arnstein -en su modelo de escalera de la participación- ubica en los peldaños más bajos la no participación (entre ellos los de manipulación y la terapia); es en los peldaños más altos donde la participación se incrementa, entre ellos el del poder delegado y el control ciudadano, aquí se obtiene mayor poder en la toma de decisiones (Arnstein, 1969: 217).

La transformación de la gestión del agua en México en los últimos 20 o 25 años supone la democratización de las estructuras de gestión, con la apertura de la participación de la sociedad organizada y de los usuarios y la iniciativa privada (Torregrosa et al, 2010). Con la reforma de 2004, la participación se contempla en la LAN principalmente a través de los Organismos y Consejos de Cuenca (y sus órganos auxiliares). En éstos últimos intervienen las instancias de los tres niveles de gobierno involucradas en el manejo del agua, los usuarios y la sociedad. Con ello, uno de los nuevos actores contemplados en la participación en la gestión del agua son los agentes privados y se consideran factores importantes en la implementación de la NGA. Una de las críticas es que la participación se promueve desde el Estado y a través de dichos Consejos. No es una que surge desde 
Año 16, Vol. 11, número 21, agosto-diciembre

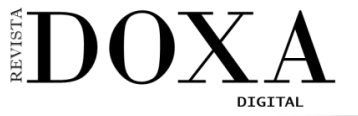

Sección: Ciencias Sociales

DOI: $10.52191 /$ rdojs.2021.219
Jesus Frausto Ortega

Gestión del agua potable...

Pág.: 72-93

la sociedad con un fin concreto (ver Musseta, 2009). En la práctica eso limita una participación democrática de todos los usuarios y de la sociedad en la política hídrica. Es una participación de arriba hacia abajo: desde los órganos de Conagua mencionados y en los OOA desde éstos hacia los usuarios. Esa conformación de arriba hacia abajo "(...) hace más difícil la conformación de un ámbito que represente legítimamente al conjunto de intereses involucrados en la territorialidad en la que operan (...) (Torregrosa et al (2010): p. 603).

En este marco normativo, los OOA se consideran como usuarios lo que también limita el involucramiento de la población común en ese nivel. Mucha de la intervención de ésta es para demandar soluciones a problemas con la gestión del agua potable (tarifas altas, falta de agua, fugas, baja presión en el sistema, etcétera) en condiciones críticas de desabasto de agua. Su colaboración en la generación de política pública del agua y en su implementación en el ámbito urbano poco o nada se da. Fuera de los grupos de interés, la inclusión de la población en la prestación del servicio del agua potable, se contempla sobre todo en los Consejos de Administración (CA) y en los Programas de Cultura del Agua (PCA). Instancias que se contemplan en la Ley de Aguas y en la política púbica nacional y local. Este tipo de participación se puede ubicar en los tipos de actores que mencionan Carabias y Landa (2005: 140) y que son los "que se involucran en su afectación del uso directo del agua", y sobre todo en la escala local. En Coahuila, la Ley de Aguas y la norma de creación del Sistema Municipal de Aguas y Saneamiento (SIMAS) contemplan el CA. De acuerdo a la primera, éste debe conformarse por un Presidente (el Presidente Municipal) y 15 Consejeros (para poblaciones de 80, 001 habitantes o más). Y los consejeros deberán "representar a las organizaciones del sector público, preferentemente miembros del cabildo, social y privado" (Congreso del Estado, 2009). El decreto de Creación de SIMAS Piedras Negras contempla que además del Presidente estará integrado por diez Consejeros (el Director de Urbanismo y Obras Públicas, el Director de Ecología, y ocho integrantes del sector privado y social). Éstos serán designados por los organismos que determine el Ayuntamiento. Además, entre otras facultades, el CA podrá aprobar las tarifas del servicio de agua (Congreso del Estado, 1993). Y de acuerdo a la Ley de referencia, los Cabildos establecerán su composición final y los organismos y personas que lo conformarán. En el caso de la cultura del agua, la ley local contempla que los organismos la promocionarán y la entiende en términos de generar conciencia [en la población] de su valor y escasez (Congreso del Estado, 2009).

\section{Metodología}

Se revisaron indicadores de gestión del agua potable de la Conagua, del Instituto Mexicano de 
Año 16, Vol. 11, número 21, agosto-diciembre

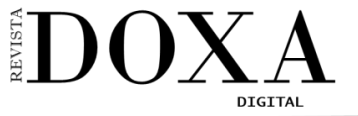

Sección: Ciencias Sociales

DOI: $10.52191 /$ rdojs.2021.219
Jesus Frausto Ortega

Gestión del agua potable...

Pág.: 72-93

Tecnología del Agua (IMTA) y de SIMAS, de 2003 a 2019: principalmente eficiencia física, eficiencia comercial y eficiencia global. Asimismo se contemplaron la micro medición, las coberturas de agua y las dotaciones, entre otros. Se consultaron minutas del Consejo de Administración de SIMAS de 2003 a 2019, de donde se obtuvo información de esos indicadores y otros relacionados con la gestión del servicio. Esto permitió complementar la información y en otros casos ver algunas diferencias en ella con el propósito que ayudaran a la reflexión. Del INEGI se obtuvo información sobre el las cobertura de agua dentro de la vivienda para el año 2015. Se realizaron dos entrevistas a funcionarios de SIMAS, una al Gerente General y otra a la responsable del Programa de Cultura del Agua: se diseñó una entrevista estructurada mediante una guía con preguntas formuladas para recabar información sobre el abasto del agua y la participación de la población en la gestión del agua en Piedras Negras. Esto complementó los datos y el conocimiento sobre el tema estudiado. En el trabajo, dicha información se presenta en forma textual de las fuentes entrevistadas. Además, se consultaron notas hemerográficas de la prensa local, así como diversas fuentes secundarias.

Es un estudio descriptivo. La revisión de los indicadores de gestión del agua mencionados condujo principalmente a poner en contexto el problema de la eficiencia en el manejo del agua. Las entrevistas, revisión de la página web sobre cultura del agua y las minutas de los Consejos de Administración ayudaron a la reflexión sobre la participación de la población en dicha gestión. Pero ambas herramientas de información además de la literatura revisada, permitieron hacer un análisis en su conjunto sobre la gestión del agua en Piedras Negras como un acercamiento a dicho tema ante la falta de estudios recientes.

\section{Gestión del Agua Potable en Piedras Negras}

Piedras Negras tiene una población de 163,595 habitantes (INEGI 2015). La fuente de abasto de agua es el río Bravo, que proporciona el 90 por ciento con las dos plantas que hay en la ciudad, alrededor de 1,000 litros por segundo. También cuenta con una galería filtrante en el Río Escondido (Rodríguez Bermea y Guzmán, 2019). Además, Rodríguez menciona que hay pozos profundos de donde se abastecen la Colonia Americana y parte de la Presidentes (La Rancherita del Aire, 2019). En 2016 Arturo Garza, director de Sistema de Aguas y Saneamiento (SIMAS) en ese momento, mencionaba que de la galería filtrante se extrae el ocho por ciento del abastecimiento del agua en la ciudad (Martínez, 2016). La extracción de agua y su potabilización se hace a través de las dos plantas: la Planta No1, inaugurada en 1964, y la No 2 que inicia operaciones en 1995. Está por inaugurarse -en 2020- una tercera Planta que reemplazará a la No1. 
Año 16, Vol. 11, número 21, agosto-diciembre

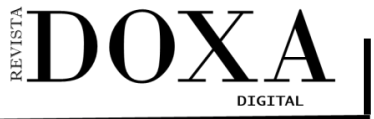

Sección: Ciencias Sociales

DOI: $10.52191 /$ rdojs.2021.219
Jesus Frausto Ortega

Gestión del agua potable...

Pág.: 72-93

En 1993 se crea SIMAS que administra el suministro de los servicios de agua potable y el drenaje en la ciudad. El abasto del agua a la población es las 24 horas al día y su falta es por lo general cuando hay algún desperfecto en la las plantas o en la red de agua potable o por alguna contingencia como fugas de agua. La cobertura en la ciudad es del 99 por ciento y del drenaje el 98 por ciento. La falta de agua la padecen los hogares irregulares que existen: "es gente que está con una casita, un posesionario, una gente que está de una manera irregular y que se conecta con el vecino (...)" (Rodríguez Bermea, 2019). El 98 por ciento de las viviendas (de 45,067) disponen de agua entubada: de éste, el 96.9 por ciento (44,330 viviendas) es dentro de la vivienda y 3.09 por ciento (1,370 viviendas) fuera de ésta pero dentro del terreno (INEGI, 2015). Los usuarios son 56 mil 427 : 47,046 doméstico; 2,175 comercial; 64 industrial; 6,942 pensionados; 200 edificios públicos (SIMAS, 2019a). Las coberturas altas se desdibujan cuándo se revisan indicadores de eficiencia y otros datos relacionados con el servicio.

En el cuadro 2 se observa que hay pérdidas de agua muy importantes: mientras que en 2003 se desperdiciaba cerca del 35 por ciento del agua que se producía, en 2017 se incrementa a un 41 por ciento y en 2019 era del 40 por ciento. Es un problema que se presenta año con año más-menos en esos porcentajes. El despilfarro obedece a las fugas, tomas clandestinas, mal uso del recurso, falta de mantenimiento de la red de agua, entre otros factores (Gobierno de Coahuila, 2012). A manera de ejemplo, en países desarrollados se aplican tecnologías que posibilitan a los organismos tener eficiencias físicas superiores al 90 por ciento y se esperaría que en México un 80 por ciento sería un valor alcanzable y razonable (Conagua, 2014b).

Cuadro 2. Eficiencias física, comercial y global de SIMAS Piedras Negras (\%)

\begin{tabular}{llllllllllllllll} 
Tipo & 2003 & 2004 & 2005 & 2006 & 2007 & 2008 & 2009 & 2010 & 2011 & 2012 & 2013 & 2014 & 2015 & 2016 & 2017 \\
\hline
\end{tabular}

\begin{tabular}{llllllllllllllll} 
E.F. & 65 & 64 & 55 & 60 & 61 & 60 & 61 & 62 & 60 & 60 & 60 & 60 & 59 & 58 & 59 \\
E.C. & 62 & 66 & 68 & 60 & 66 & 66 & 66 & 66 & 66 & 86 & 79 & 83 & 83 & 84 & 88 \\
E.G. & 40 & 42 & 37 & 36 & 40 & 39 & 40 & 41 & 39 & 52 & 48 & 50 & 49 & 49 & 52 \\
\hline
\end{tabular}

Fuente: Datos tomados de IMTA. PIGOO, 2019.

Nota: los porcentajes se redondearon. EF: Eficiencia Física; EC: Eficiencia Comercial; EG; Eficiencia Global; corresponden a los valores consultados el 10 de enero de 2019.

Le eficiencia comercial es donde se observa mayores progresos, ésta es en 2017 del 88 por ciento, mientras en 2003 era un poco más del 60 por ciento valor que se conserva (mas-menos) hasta 2011. Esto es, ahora se recauda más por el agua que se factura de lo que se hacía en aquél 
Año 16, Vol. 11, número 21, agosto-diciembre

DOXA
Sección: Ciencias Sociales

DOI: 10.52191/rdojs.2021.219
Jesus Frausto Ortega

Gestión del agua potable...

Pág.: 72-93

año. En cuanto a la eficiencia global, ésta es en promedio de 50 por ciento en los últimos años; de la misma manera, es una problemática que se presenta año con año si bien ahora esa eficiencia es un poco mejor que en años anteriores: en 2003 era de un 40 por ciento y en 2017 es del 52 por ciento. En ese sentido, el desempaño del organismo en el manejo del agua enfrenta rezagos importantes y como tal en lo que se cobra por ella. Ese escenario no parece halagador si se revisan otras fuentes. Por ejemplo, en 2013 la Conagua (2014a) reportaba una eficiencia física del 52 por ciento, la comercial del 76 por ciento y la global de 39 por ciento.

Otros indicadores también nos ayudan a entender el problema de la eficiencia en el manejo del agua potable. El agua que no se contabiliza de la que se produce nos refuerza el de las pérdidas físicas de agua o la falta del pago real por el consumo: en 2006 era del 43 por ciento y en 2013 del 48 por ciento (Conagua, 2007 y 2014a). La falta de contabilidad de agua tiene que ver entre otras cosas con la falta de medidores. Como se observa en el cuadro 3, en 2012 el 43 por ciento de las tomas no tienen medidor, no sirven o no funcionan. Poco se ha avanzado ya que en 2017 la medición es del 52.9 por ciento (IMTA, 2019).

Cuadro 3. Micromedición en las tomas de agua en Piedras Negras, Coahuila.

\begin{tabular}{cccccc}
\hline Año & $\begin{array}{c}\text { Tomas con medi- } \\
\text { dores* }\end{array}$ & \% & $\begin{array}{c}\text { Tomas sin medi- } \\
\text { dores** }\end{array}$ & \% & Total \\
\hline 2006 & 29081 & 76.7 & 8825 & 23.3 & 37906 \\
2009 & 25834 & 60.2 & 17053 & 39.8 & 42887 \\
2012 & 26909 & 56.7 & 20565 & 43.3 & 47474 \\
\hline
\end{tabular}

Fuente: Elaboración propia con datos de CONAGUA, 2007, 2010, 2013.

* Se refiere de las tomas de agua con medidores instalados y con lectura

** Se refiere de las tomas de agua con medidores sin lectura o sin funcionar y sin medidor instalado

Si bien la instalación de medidores ha sido una preocupación del OOA. Eso se refleja en las reuniones de los CA: así, se habla que en 2013 se instalaron 2,266 medidores, en 2014 fueron 4,188 y en 2015 se pusieron 6,019 (SIMAS, 2015cd). De acuerdo con Julia Ortega Urteaga, Gerente Comercial de SIMAS, ésta institución instalará 7 mil medidores que es el rezago que se tiene y corresponde al sector doméstico, pues los sectores comercial, industrial y comercial menor están completamente medidos (Rodríguez, 2018). Esto es, se consideraba que para ese año 2018 se tuviera el 100 por ciento de la cobertura. Pero como se señaló, eso no se ha logrado. La falta de medición del agua y el desperdicio se reflejan también en las dotaciones altas que hay del líquido. En 2006 era de 398 litros por habitante por día, mientras que en los años 2009 era de 452 y en 2012 
Año 16, Vol. 11, número 21, agosto-diciembre

DOXA
Sección: Ciencias Sociales

DOI: $10.52191 /$ rdojs.2021.219
Jesus Frausto Ortega

Gestión del agua potable...

Pág.: 72-93

de 574 (Conagua, 2007 y 2013). Sobre los factores del desperdicio de agua en la ciudad el Gerente de SIMAS menciona:

Uno. Por la antigüedad de las líneas (...). Segundo, por la falta de micro medición, de medidores en las casas que gente al tener una cuota fija no cuida el agua. Tercero, daños que hay de repente en las líneas generales. En las casas es muy común que cuando les cortas el servicio, ellos van y se reconectan solos, (...) y ahí hay mucho desperdicio de agua [...] (Rodríguez Bermea, 2019).

Si bien, como se mencionó, el agua cobrada de la facturada se ha incrementado, los datos varían sobre el agua cobrada de la enviada (cuadro 4). Así, del agua que se enviaba en 2014 solo se cobraba el 54 por ciento. Incluso, si se relaciona con el agua facturada se ve que solo el 65 por ciento se cobraba.

Cuadro 4. Agua enviada, facturada y cobrada en Piedras Negras

\begin{tabular}{cccccc}
\hline Año & Enviada & Facturada & $\%$ & Cobrada & $\%$ \\
\hline 2011 & 20 & 13.1 & 65.5 & 10.7 & 53.5 \\
2012 & 22.8 & 13.7 & 60.1 & 11.8 & 51.8 \\
2013 & 23 & 13.8 & 60.0 & 10.9 & 47.4 \\
2014 & 22.23 & 14.51 & 65.3 & 12.05 & 54.2 \\
\hline
\end{tabular}

Fuente: Elaboración con datos de SIMAS 2015b. * Millones de metros cúbicos

* Millones de metros cúbicos

En el cobro del agua, las autoridades actuales han reconocido ese problema. El Director General de SIMAS, Teodoro Rodríguez, informa que se creó el Departamento de Cuentas por Cobrar para solventar el problema, se ha detectado que hay usuarios que tienen hasta 90 meses sin pagar, que nunca fueron sancionados y estuvieron involucrados empleados del organismo por corrupción; por ello, se ordenó cortar el agua a 3 mil usuarios que representan un adeudo de 37 millones de pesos (Martínez, 2019b). Además, el presidente municipal mencionaba que SIMAS tiene una deuda de 52 millones de pesos: "EI Simas en sí financieramente está en números rojos, no tiene capacidad para cubrir su gasto corriente, mucho menos para el rubro de inversión". (Martínez, 2019a). Además, las tarifas las autoriza el Congreso y no puedes "cobrar más de eso", lo que se cobra por metro cúbico es de entre 6 y 7 pesos; "es un precio muy barato, por una cuestión política [...]" (Rodríguez Bermea, 2019). Gran parte del presupuesto de SIMAS se va en sueldos. Entre sueldos y energía eléctrica se deroga cerca del 80 por ciento de los ingresos de SIMAS (47 por ciento en servicios perso- 
Año 16, Vol. 11, número 21, agosto-diciembre

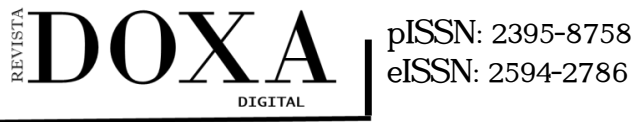

Sección: Ciencias Sociales

DOI: $10.52191 /$ rdojs.2021.219
Jesus Frausto Ortega

Gestión del agua potable...

Pág.: 72-93

nales y 30 por ciento en energía) (SIMAS, 2015e). El Gerente de SIMAS menciona:

[...] Cuándo avanzas, así tengas 50,000 tomas. [...], si nomás de nómina son cerca de 5 millones y pico y de luz 3 millones y pico [...] Los principales rubros son nómina, Comisión Federal y mantenimiento de líneas. Es a donde se va el 90 por ciento del presupuesto (Rodríguez Bermea, 2019).

También señala que se incorporaron cuentas por cobrar de escuelas públicas, estatales y federales, oficinas de gobierno, Hacienda, Puente Internacional No 2, IMSS y Municipio, ya que "antes solo se facturaba, [ahora] ya se paga el servicio". Sobre los jubilados, se encontró que de los 12,761 que se reportaban solo eran la mitad: 6,942.

Con relación a la participación de la población en la gestión del agua: En el ámbito del OOA, la sociedad en general poco participa en la gestión del agua en la ciudad. En la toma de decisiones sobre la administración del servicio es sobre todo a través de actores de las cámaras locales involucrados en los CA y mediante los PCA para que la población atendida reciba información y genere conciencia del cuidado del agua y de su pago. De acuerdo con el Gerente de SIMAS la inclusión de la población se hace principalmente a través del cumplimiento en el pago del servicio de agua y añade que se está tratando de fomentar en las escuelas la cultura del agua, de la educación, y del cuidado del agua y de no desperdiciarla (Rodríguez Bermea, 2019).

EI CA está conformado principalmente por instituciones públicas del gobierno municipal, de la iniciativa privada local y las denominadas asociaciones civiles de la ciudad (las denominadas "fuerzas vivas"). Las que normalmente han participado desde 2003 (cuando se instituye SIMAS) hasta 2015 son:

Públicas: Presidencia Municipal; Planeación, Urbanismo y Obras Públicas. Privadas y Asociaciones Civiles: Colegio de Notarios del Estado de Coahuila, Cámara Nacional de Comercio y Servicios y Turismo, CANACINTRA, Consejo de la Industria Maquiladora A. C., Club Rotario de Piedras Negras A. C., Asociación de Agentes Aduanales, Colegio de Ingenieros Civiles del Norte de Coahuila, Complejo Industrial San Luis Rassini (SIMAS, 2005 y 2014).

A finales de 2017 participa la Comisión Federal de Electricidad. Otros actores públicos que no se especifica si son o no miembros del Consejo dado que no se les identifica como Titulares o Suplentes son: a) Desarrollo Municipal; b) Planta de Tratamiento de Aguas Residuales; c) Parques y Jardines; d) Desarrollo Urbano; e) Seguridad Ambiental, f) Instituto Municipal de Planeación (IMPLAN) (SIMAS, 2017 y 2018). Actualmente también se han integrado al Consejo actores de instituciones privadas como la Cervecera Constelation Brands y Triturados de Piedras Negras. Sobre el Consejo 
Año 16, Vol. 11, número 21, agosto-diciembre

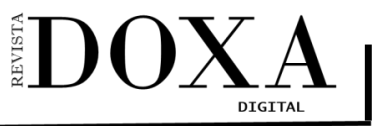

Sección: Ciencias Sociales

DOI: 10.52191/rdojs.2021.219
Jesus Frausto Ortega

Gestión del agua potable...

Pág.: 72-93

el Gerente de SIMAS menciona:

Hay un Consejo de Administración que es independiente [...] El Alcalde mete unas propuestas y el Consejo decide. Es un Consejo en donde están todos los presidentes de las cámaras, todas las áreas, las fuerzas vivas. Son 10,12 consejeros, se hace la propuesta y la votación a una terna que presenta el alcalde (Rodríguez Bermea, 2019).

Como se mencionó, la otra forma de participación de la población es a través del PCA. Entre sus objetivos están: promover el uso eficiente y el ahorro del agua; crear conciencia en la población sobre la importancia de pagar oportunamente el servicio de agua; hacer visitas guiadas a la planta potabilizadora para dar a conocer el proceso de potabilización y generar conciencia en la población (SIMAS, 2019b). De acuerdo con la responsable del programa éste se divide en uno permanente y otro que se va conformando según acontece algún evento o lo requiera la población:

En el permanente se tratan tres aspectos: 1. Programamos (...) vistas a la planta potabilizadora (...) para que la ciudadanía conozca el proceso que tiene la potabilización del agua en nuestra ciudad. Ahí van escuelas [de todos los niveles educativos], van también sectores privados. 2) (...) visitas a instituciones educativas o empresariales y; 3 ) damos conferencias, que se hacen tomando alguna rama especializada que tenemos aquí en el organismo (...). (Guzmán, 2019).

Sin embargo, este programa no se evalúa sobre sus impactos en la población en el ahorro del agua. Esto concuerda con lo encontrado en otros trabajos con la falta de efectividad en la evaluación de los PCA (González y Arzaluz, 2011). Así, la participación de la población en gestión del agua es mínima. Se reduce a lo que hacen los representantes de las cámaras locales en el CA: conocer y votar los acuerdos sobre indicadores de la administración y el manejo del agua. Los que participan en el PCA son meros receptores de información y conocimientos generales sobre el tema agua, a quienes se les persuade para ahorrar y cuidar el agua, así como a pagarla, entre otras acciones.

\section{Conclusiones}

En Piedras Negras, Coahuila se tiene coberturas altas en agua potable y alcantarillado: 99 y 98 por ciento, respectivamente. Pero, como se mostró, entre los problemas en la gestión está la falta de eficiencia en el manejo del agua. El 40 por ciento del agua que se produce se pierde en fugas, tomas clandestinas, mal uso, falta de mantenimiento de las redes y otros. Esto se traduce en desperdicios de agua y como tal en la calidad del agua y del servicio que se presta, además presiona a la fuente principal de extracción del líquido: el río Bravo. Así, los ahorros que se pudieran obtener con un manejo más eficiente del líquido ayudarían a aliviar la cantidad de agua extraída que es cercana 
Año 16, Vol. 11, número 21, agosto-diciembre

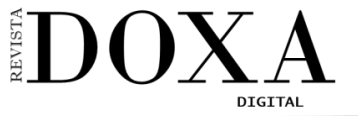

Sección: Ciencias Sociales

DOI: $10.52191 /$ rdojs.2021.219
Jesus Frausto Ortega

Gestión del agua potable...

Pág.: 72-93

a los 1000 l/s; el agua ahorrada -considerando lo que se puede alcanzar en el país- pudiera utilizarse en demandas venideras: la eficiencia física es del 59 por ciento y se esperaría que en México se pudiera alcanzar y es razonable un 80 por ciento (Conagua 2014b). El problema de eficiencia se presenta de manera recurrente en los años revisados, de 2003 a 2019. Se ha avanzado en la eficiencia comercial. Pero el cobro total por el agua producida sigue siendo tema pendiente: la eficiencia comercial es del 88 por ciento en 2017. La situación se agrava para el OOA ya que se cobra entre 6 y 7 pesos por metro cúbico y eso "es un precio muy barato por una cuestión política". Así, en 2019 "El SIMAS en sí financieramente está en números rojos, no tiene capacidad para cubrir su gasto corriente, mucho menos para el rubro de inversión" (Martínez, 2019ab). El valor del agua que se contempla en la provisión del servicio es el económico a través de las tarifas buscando que cubran los costos de operación y mantenimiento, pero como se vio esto no se ha logrado. Así, el desempeño en la gestión del agua y del servicio por parte de SIMAS es el reto a resolver. En términos generales, los problemas de eficiencia mostrados concuerdan con los referidos por la literatura revisada y citada en este documento.

La participación de la sociedad en la gestión del agua es mínima. Ella se reduce a la inclusión de actores en el CA a invitación de las autoridades y se involucran principalmente responsables de organismos empresariales o líderes de éstos que apoyan la beneficencia social; más allá, la población no participa en la política del agua. La otra forma de hacerlo es a través del PCA por el cual se persuade a la sociedad atendida sobre la importancia del ahorro del agua, el pago del servicio y a no contaminarla. De esta manera la gente a la que llega el PCA es mera receptora de información y conocimiento sobre el tema. Además, el programa no se evalúa para conocer su impacto en el ahorro del agua por parte de los usuarios. En general, los resultados reportados aquí sobre la participación social en la política local del agua y del poco impacto de los PCA concuerdan con la literatura regional sobre el tema: la mínima participación social en la gestión del agua (González y Arzaluz, 2011; Arzaluz, 2011).

Una de las propuestas de política sería que el OOA local replanteara su labor en la gestión del agua haciendo más eficiente tanto su manejo como la prestación del servicio, antes que buscar nuevas fuentes de agua que son escasas; esto con el fin de ahorrar agua y recursos económicos destinados a en la producción de agua potable que se desperdicia. Pues es un problema recurrente. Medir el agua que se extrae y se consume y cobrarla en su totalidad es parte de esa sugerencia. Para ello, el mantenimiento de la red de agua potable y el control de fugas, de manera constante, es importante. El problema obedece en parte a la antigüedad de las líneas y a la falta de micromedi- 
Año 16, Vol. 11, número 21, agosto-diciembre

DOXA
Sección: Ciencias Sociales

DOI: $10.52191 /$ rdojs.2021.219
Jesus Frausto Ortega

Gestión del agua potable...

Pág.: 72-93

ción que en 2017 era del 52 por ciento y aún hoy no se tiene el 100 \%. En conjunto con la ciudadanía debe buscarse una mayor participación de ésta en la política hídrica local, inicialmente puede hacerse a través de incorporar a la población común en los CA aunque hay que hacer modificaciones al marco normativo local para posibilitar dicha inclusión. EI PCA debe ser evaluable para ver sus impactos en el ahorro del agua e instituirlo como una política pública permanente e inclusiva para toda la población.

\section{Referencias}

Aboites Aguilar, L.; Birrichaga Gardica, D.; Garay Trejo J.A. El manejo del agua en el siglo XX. En B. Jiménez Cisneros; Ma. L. Torregrosa y Armentia y L. Aboites Aguilar (Edits.). El agua en México. Cauces y encauces. (pp. 21-49). México: Academia Mexicana de Ciencias/ CONAGUA. Recuperado de http://www.conagua.gob.mx/CONAGUA07/Contenido/ Documentos/elaguaenmexico-caucesyencauces.pdf.

ANEAS (2015). Gobernanza del agua en México. Recuperado de https://aneas.com.mx/gobernanza -del-agua-en-mexico/.

Armendáriz Torres S. (2010). Organismos operadores del agua en México [tesis de maestría]. Universidad Autónoma Metropolitana. Recuperada de https://core.ac.uk/download/ pdf/48392368.pdf.

Arzaluz, S. (2011). Los servicios públicos en los gobiernos mexicanos: una mirada en la gestión del agua en municipios fronterizos. En I. Aguilar Benítez (Coord.). Los servicios del agua en el norte de México. Gestión, manejo financiero y aspectos ambientales. (pp. 25-64). México: El Colegio de la Frontera Norte/El Colegio de Sonora.

Arreguin Cortés, F I.; Alcocer Yamanaka, V.; Morengo Mogollón, H.; Cervantes Jaimes, C; Albornóz Góngora, P.; y Salina Juárez M. G. (2010). Los retos del agua. En Blanca Jiménez Cisneros; Ma. Luisa Torregrosa y Armentia y Luis Aboites Aguilar (Edits.). El agua en México. Cauces y encauces. (pp. 51-77). México: Academia Mexicana de Ciencias/CONAGUA. Recuperado de http://www.conagua.gob.mx/CONAGUA07/Contenido/Documentos/elaguaenmexicocaucesyencauces.pdf.

Arnstein, Sherry R. (1969) 'A Ladder Of Citizen Participation', Journal of the American Planning Association, 35: 4, 216-224. DOI: 10.1080/01944366908977225.

Cámara de Diputados (1992). Ley de Aguas Nacionales. Recuperado de http:// www.diputados.gob.mx/LeyesBiblio/pdf/16_240316.pdf. 
Año 16, Vol. 11, número 21, agosto-diciembre

DOXA
Sección: Ciencias Sociales

DOI: 10.52191/rdojs.2021.219
Jesus Frausto Ortega

Gestión del agua potable...

Pág.: 72-93

Carabias, J. y R. Landa (2005). La participación social en la gestión integral del agua (Capítulo 11). Agua, medio ambiente y sociedad. Hacia una gestión integran de los recursos en México. Recuperado de http://www.bibliotecavirtual.info/recursos/agua_medio_ambiente_y_sociedad.pdf

Carrillo G. y Constantino R. (2010). El Manejo del recurso hídrico, ¿escasez o un modelo de gestión inadecuado en México? En Montero, D., Gómez, E., Carrillo G., Rodríguez, L. Innovación tecnológica, cultura y gestión del agua. Nuevos retos del agua en el Valle de México. (pp. 119135). México: UAM/Porrúa.

Comisión Nacional del Agua (Conagua) (2014a). Situación del Subsector Agua Potable Alcantarillado y Saneamiento. Edición 2014. Recuperado de https://www.gob.mx/cms/uploads/ attachment/file/109703/DSAPAS_2014_2de2.pdf.

Conagua (2014b). Manual de Indicadores de Gestión. Recuperado de https://

aguapotabledeloscabos.gob.mx/wp-content/uploads/2016/02/INDICADORES-DE-GESTION20140001-entregados-1.pdf.

Conagua (2013). Situación del Subsector Agua Potable Alcantarillado y Saneamiento. Edición 2013. Recuperado de https://www.gob.mx/cms/uploads/attachment/file/108997/DSAPAS_2013.pdf. Conagua (2010). Situación del Subsector Agua Potable Alcantarillado y Saneamiento. Edición 2010. Recuperado de https://www.gob.mx/cms/uploads/attachment/file/108994/DSAPAS_2010.pdf. Conagua (2007). Situación del Subsector Agua Potable Alcantarillado y Saneamiento. Edición 2007. Recuperado de https://www.gob.mx/cms/uploads/attachment/file/108991/DSAPAS_2007.pdf. Congreso del Estado de Coahuila (2009). Ley de Aguas para los Municipios del Estado de Coahuila de Zaragoza. Recuperado de http://www.ordenjuridico.gob.mx/Documentos/Estatal/Coahuila\% 20de\%20Zaragoza/wo57490.pdf.

Congreso del Estado de Coahuila (1993). Ley que crea el organismo público descentralizado denominado Comisión Estatal de Aguas y Saneamiento de Coahuila. Recuperado de https:// www.sema.gob.mx/descargas/legal/leyes/Ley_Organismo_Descentralizado_CEAS_2017.pdf.

Dávila Poblete, S. (2006). El poder del agua. ¿Participación social o empresarial? México, experiencia piloto del neoliberalismo para América Latina. México: Itaca.

Gobierno de Coahuila (2012). Programa especial. Agua potable, drenaje y saneamiento. Recuperado de https://coahuila.gob.mx/archivos/pdf/Publicaciones/PROGRAMA\%20ESPECIAL\% 20DE\%20AGUA\%2011-17.pdf.

González, M. E. y Arzaluz, S (2011). El Programa de Cultura del Agua en el noreste de México. ¿Concepto utilitario, herramienta sustentable o requisito administrativo? Región y Sociedad, 23 
Año 16, Vol. 11, número 21, agosto-diciembre

DOXA
Sección: Ciencias Sociales

DOI: 10.52191/rdojs.2021.219
Jesus Frausto Ortega

Gestión del agua potable...

Pág.: 72-93

(51), pp. 123-160. México: El Colegio de Sonora. Recuperado de http://www.scielo.org.mx/ scielo.php?script=sci_arttext\&pid=S1870-39252011000200005.

Guzmán, N. (6 de junio de 2019). Gestión del agua potable en Piedras Negras. El Colegio de la Frontera Norte. Piedras Negras, Coahuila.

GWP (2011). ¿Qué es la GIRH? Recuperado de https://www.gwp.org/es/GWP-Sud-America/ ACERCA/por-que/PRINCIPALES-DESAFIOS/Que-es-la-GIRH/ Instituto Nacional de Geografía e Informática (INEGI). (2015). Recuperado de https:// www.inegi.org.mx/contenidos/programas/intercensal/2015/tabulados/14_vivienda_coah.xls. Instituto Mexicano de Tecnología del Agua (IMTA) (2019). Recuperado de http://www.pigoo.gob.mx/ descargarData.jsp.

La Rancherita del Aire (17 de septiembre de 2019). La Rancherita del Aire. Recuperado de https:// rancherita.com.mx/noticias/detalles/72423/problemas-de-baja-presion-en-nueva-americanason-por-bajo-nivel-del-pozo-que-suministra-agua-simas.html\#.XYRNHC5KjIW.

Martínez, L (2 de enero de 2019a). Crece deuda detectada en Simas a 52 MDP. El Zócalo Recuperado de http://www.zocalo.com.mx/new_site/articulo/crece-deuda-detectada-en-simas-a-52mdp.

Martínez, L (29 de marzo de 2019b). Simas realizará crtes a 3 mil usuarios. El Zócalo. Recuperado de https://www.zocalo.com.mx/new_site/articulo/simas-realiza-cortes-a-tres-mil-usuarios.

Martínez, L. (20 de julio de 2016). Realizan mantenimiento en galería filtrante. El Zócalo. Recuperado de https://www.zocalo.com.mx/new_site/articulo/realizan-mantenimiento-en-galeria-filtrante $-1469008388$.

Mussetta, P. (2009). Participación y gobernanza. El modelo de gobierno del agua en México Espacios Públicos, vol. 12(25), pp. 66-84. Universidad Autónoma del Estado de México Toluca, México. Recuperado de https://www.redalyc.org/pdf/676/67611350005.pdf.

Naciones Unidas (1987). Informe de la Comisión Mundial sobre el Medio Ambiente y el Desarrollo.

Recuperado de https://undocs.org/es/A/42/427.

Organización de las Naciones Unidas (ONU) (1997). Declaración de Río sobre el Medio Ambiente y el Desarrollo: aplicación y ejecución. Recuperado de https://documents-dds-ny.un.org/doc/ UNDOC/GEN/N97/013/69/PDF/N9701369.pdf?OpenElement

Organización de las Naciones Unidas (ONU) (Sin fecha). Programa 21: Capítulo 18. Recuperado de https://www.un.org//spanish/esa/sustdev/agenda21/agenda21spchapter18.htm. 
Año 16, Vol. 11, número 21, agosto-diciembre

DOXA
Sección: Ciencias Sociales

DOI: 10.52191/rdojs.2021.219
Jesus Frausto Ortega

Gestión del agua potable...

Pág.: 72-93

Pineda Pablos, N. Salazar Adams, A. y Rodríguez Buenfil, M. En B. Jiménez Cisneros, M. L. Torregrosa, y L. Aboites Aguilar, L. (2010). Para dar de beber a las ciudades mexicanas: el reto de la gestión eficiente del agua ante el crecimiento urbano. Blanca Jiménez Cisneros María Luisa Torregrosa y Armentia Luis Aboites Aguilar (Edts.). El auge en México. Causas y encauces. (pp. 115-140). México: Academia Mexicana de Ciencias/CONAGUA. Recuperado de http:// www.conagua.gob.mx/CONAGUA07/Contenido/Documentos/elaguaenmexicocaucesyencauces.pdf.

Pineda, Pablos N. (2008). Nacidos para perder dinero y derrochar agua. El inadecuado marco institucional de los organismos operadores de agua en México. En D. Soares; S. Vargas y M. R. Nuño. La gestión de los recursos hídricos. Realidades y perspectivas. (Tomo I). (pp. 121-150). Guadalajara, Jalisco: Instituto Mexicano de Tecnología del Agua/Universidad de Guadalajara. Recuperado de http://repositorio.imta.mx/handle/20.500.12013/1160.

Pineda, Pablos N. (2002). La política urbana de agua potable en México: del centralismo y los subsidios a la municipalización, la autosuficiencia y la privatización. Región y Sociedad. Vol. XIV. No. 24.

Rodríguez Bermea, T. (24 de mayo de 2019). Gestión del agua potable en Piedras Negras. El Colegio de la Frontera Norte. Piedras Negras, Coahuila.

Rodríguez, J. (28 de marzo de 2018). Instalarán siete mil medidores para agua potable en Piedras Negras. Vanguardia. Recuperado de https://vanguardia.com.mx/articulo/instalaran-siete-milmedidores-para-agua-potable-en-piedras-negras.

Rolland L. y Vega Cárdenas Y. (2010). La gestión del agua en México. Recuperado de http:// www.scielo.org.mx/pdf/polis/v6n2/v6n2a6.pdf.

SER/SEMARNAT (2008). Declaración de Dublín sobre el agua y el Desarrollo Sostenible. Recuperado de https://www.cimacnoticias.com.mx/documentos/cambio_climatico/ conf_inter_sobre_agua_y_medio_ambiente.pdf

Sistema Municipal de Aguas y Saneamiento (SIMAS) (2005). Consejo Directivo del Sistema Municipal de Aguas y Saneamiento. 14 de enero. Recuperado de http://simaspiedrasnegras.gob.mx/ Transparencia/informacion/13.-Reuniones\%20del\%20Consejo\%20General/reuniones/2005/0114-05.pdf.

SIMAS (2014). Reunión ordinaria del Consejo de SIMAS. 27 de noviembre. Recuperado de http:// www.simaspiedrasnegras.gob.mx/Transparencia/informacion/13.-Reuniones $\% 20 \mathrm{del} \%$ 20Consejo\%20General/reuniones/2014/ACTA-271114.pdf. 
Año 16, Vol. 11, número 21, agosto-diciembre

DOXA
Sección: Ciencias Sociales

DOI: 10.52191/rdojs.2021.219
Jesus Frausto Ortega

Gestión del agua potable...

Pág.: 72-93

SIMAS (2017). Reunión ordinaria del Consejo de SIMAS. 29 de diciembre. Recuperado de http:// www2.icai.org.mx/ipo/archives/74/56646728-12Diciembre2017.pdf.

SIMAS (2018). Reunión ordinaria del Consejo de SIMAS. 30 de enero. Recuperado de http:// www2.icai.org.mx/ipo/archives/74/35223388-01Enero.pdf.

SIMAS (2015c). Presentación de 12 de diciembre. http://www.simaspiedrasnegras.gob.mx/ Transparencia/informacion/13.-Reuniones\%20del\%20Consejo\%20General/reuniones/2015/ presentaciones/12\%20Diciembre\%202015).pdf.

SIMAS (2015d) Presentación de enero. Recuperado de http://www.simaspiedrasnegras.gob.mx/ Transparencia/informacion/13.-Reuniones\%20del\%20Consejo\%20General/reuniones/2015/ presentaciones/ENERO\%202015.pdf.

SIMAS (2015b). Presentación del Consejo de SIMAS. 5 de mayo recuperado de http:// www.simaspiedrasnegras.gob.mx/Transparencia/informacion/13.-Reuniones\%20del\% 20Consejo\%20General/reuniones/2015/presentaciones/5\%20MAYO\%202015\%20(abril).pdf.

Simas (2015e). Reunión ordinaria del Consejo de SIMAS. 29 de enero. Recuperado de http:// www.simaspiedrasnegras.gob.mx/Transparencia/informacion/13.-Reuniones\%20del\% 20Consejo\%20General/reuniones/2015/ACTA\%2029012015.pdf

SIMAS (2019b). Programa de Cultura del Agua. Recuperado de http:// www.simaspiedrasnegras.gob.mx/que-es-cultura-del-agua/.

SIMAS (2019a). Presentación 28 de junio. Recuperado de http://www2.icai.org.mx/ipo/ dependencia.php?dep=74\#pageload.

Schmidt, G. (2005). Cambios legales e institucionales hacia la privatización del agua en México. Recuperado de http://www.bvsde.paho.org/bvsacd/cd59/agua-mexico.pdf.

Torregrosa, M. L; Paré L. O.; Kloster, K.; Vera, J. (2010). Administración del agua. Blanca Jiménez Cisneros María Luisa Torregrosa y Armentia Luis Aboites Aguilar (Edts.). El auge en México. Causas y encauces. México: Academia Mexicana de Ciencias/CONAGUA. Recuperado de http://www.conagua.gob.mx/CONAGUA07/Contenido/Documentos/elaguaenmexicocaucesyencauces.pdf.

Shiva, V. (2007). Las guerras del agua. Privatización, contaminación y lucro. México: Siglo XXI. Valencia Flores L. M y R. Molina Martínez (2013). La gestión del agua un reto gubernamental. México: Porrúa. 